\title{
UM MUTIRÃO DE VOZES, ROSTOS E AÇÕES: UMA LEITURA DAS PAISAGENS DA FESTA-ROMARIA DE TRINDADE, GOIÁS ${ }^{1}$
}

\author{
Eguimar Felício Chaveiro ${ }^{2}$ \\ Ricardo Junior de Assis Fernandes Gonçalves ${ }^{3}$ \\ Helsio Amiro Motany de Albuquerque Azevedo ${ }^{4}$
}

\section{Resumo}

A Festa-Romaria de Trindade/GO aglutina rostos e tradições, sintetiza manifestações simbólicas do catolicismo e ao mesmo tempo, modifica as paisagens, organiza o território e o trabalho, intensifica a dinâmica econômica local e revela as mudanças culturais de Goiás. É também fonte de acontecimentos e especialmente de disputas pelo controle de territórios por atores hegemônicos como o Estado, a Mídia, a Polícia e a Gestão Municipal. Em função disso, o problema que ampara as reflexões que norteiam esse artigo é: como enxergar na apropriação diversa da Festa-Romaria de Trindade as transformações do território goiano? A metodologia utilizada na pesquisa baseia-se em procedimentos qualitativos como pesquisa de campo, registros fotográficos, observação direta e entrevistas. A pesquisa revela que a FestaRomaria de Trindade apresenta indicativos de transformação da inserção do território goiano a partir da cultura de seu povo no país e no mundo. Mas, também há permanências que tecem saberes, símbolos e sociabilidades deste povo e sua cultura.

Palavras-chave: Festa-Romaria de Trindade. Turismo Religioso. Paisagem. Trabalho.

\footnotetext{
${ }^{1}$ A primeira versão deste texto foi apresentada em forma de Resumo Expandido com o título 'Paisagens da Festa-Romaria de Trindade: um retrato múltiplo de Goiás', no I Simpósio Internacional e II Nacional Manifestações do Catolicismo, realizado na Universidade Federal de Goiás - UFG, de 03 a 07 de setembro de 2013. Sendo assim, desde 2013 os pesquisadores realizam pesquisas de campo no contexto da Festa-Romaria de Trindade, reunindo relatos de entrevistas, registros áudios-visuais e anotações em cadernos de campo. Por consequência, parte destes resultados é apresentada neste texto.

${ }^{2}$ Professor Doutor da Graduação e Pós-Graduação em Geografia do Instituto de Estudos Socioambientais da Universidade Federal de Goiás - IESA/UFG. E-mail: eguimar@hotmail.com.

${ }^{3}$ Professor Auxiliar e Diretor-Adjunto para a Investigação e Extensão na Universidade Eduardo Mondlane, Escola Superior de Hotelaria e Turismo, Moçambique. E-mail: helsio.azevedo@ hotmail.com.

${ }^{4}$ Professor Doutor do Curso de Geografia da Universidade Estadual de Goiás - Campus Iporá. Professor do Mestrado em Língua, Literatura e Interculturalidade - POSLLI, da UEG - Campus Cora Coralina. E-mail: ricardo.goncalves@ueg.br.
} 


\title{
AN BROUGHT TOGETHER OF VOICES, FACES AND ACTIONS: A READING OF THE LANDSCAPES OF THE FEAST-PILGRIMAGE OF TRINDADE, GOIÁS
}

\begin{abstract}
The Feast- Pilgrimage of Trindade / GO brings together faces and traditions, synthesizes symbolic manifestations of Catholicism and at the same time, modifies landscapes, organizes territory and work, intensifies the local economic dynamics and reveals the cultural changes of Goiás. It is also a source of events and especially disputes over the control of territories by hegemonic actors such as the State, the Media, the Police and Municipal Management. As a result, the problem that underlies the reflections that guide this article is: how to see the transformations of Goiano territory in the different appropriation of the Feast- Pilgrimage of Trindade? The methodology used in the research is based on qualitative procedures such as field research, photographic records, direct observation and interviews. The research reveals that the Holy Trinity Festival presents indicatives of transformation of the insertion of the Goiano territory from the culture of its people in the country and in the world. But there are also permanences that weave knowledge, symbols and sociabilities of this people and their culture.
\end{abstract}

Key Words: Feast-Pilgrimage of Trindade. Religious Tourism. Landscape. Work.

\section{UNA REUNION DE VOCES, ROSTROS Y ACCIONES: UNA LECTURA DE LOS PAISAJES DE LA FIESTA- PEREGRINACIÓN DE TRINDADE, GOIÁS}

\section{Resumen}

La Fiesta-Peregrinación de Trindade / GO aglutina rostros y tradiciones, sintetiza manifestaciones simbólicas del catolicismo y al mismo tiempo, modifica los paisajes, organiza el territorio y el trabajo, intensifica la dinámica económica local y revela los cambios culturales de Goiás. Es también fuente de acontecimientos y especialmente de disputas por el control de territorios por actores hegemónicos como el Estado, los Medios, la Policía y la Gestión Municipal. En función de ello, el problema que ampara las reflexiones que orientan este artículo es: ¿cómo ver en la apropiación diversa de la Fiesta-Peregrinación de Trinidad las transformaciones del territorio goiano? La metodología utilizada en la investigación se basa en procedimientos cualitativos como investigación de campo, registros fotográficos, observación directa y entrevistas. La investigación revela que la Fiesta-Romería de Trindade presenta indicativos de transformación de la inserción del territorio goiano a partir de la cultura de su pueblo en el país y en el mundo. Pero, también hay permanencias que tejen saberes, símbolos y sociabilidades de este pueblo y su cultura.

Palabras clave: Fiesta-Peregrinación de Trindade. Turismo Religioso. Paisaje. Trabajo.

\section{INTRODUÇÃO}




\section{Cenas de uma Festa-Romaria...}

Cena 1 - Seu Zé e Dona Maria, há mais de 30 anos instalam a sua barraca no fundo da mesma casa um dia antes de começar a primeira novena. Ele, a sua esposa e os seus filhos são tratados como parentes pelo morador trindadense, mas paga o aluguel do quintal. Em $2013 \mathrm{fez}$ 25 anos que acompanha todas as novenas. Isso é o que há de mais sagrado na sua vida e na vida de sua família. Se não participar das novenas - diz o seu Zé - alguma coisa ficou faltando em sua vida. Já veio de carro de boi, de carroça, agora vem de camionete, aliás, traz sempre muitos biscoitos, doces e presentes para a dona da casa. Tornaram-se amigos, ela já saiu de Trindade e visitou a sua fazenda no interior do território goiano. "Tudo falha na vida, meu filho, menos o Divino Pai Eterno. A festa é boa também para aproveitar e fazer umas comprinhas para a fazenda".

Cena 2 - Tem 15 anos que monta a sua barraca de vender pastel. Às vezes não ganha muito dinheiro, não - diz a senhora de tem em torno de 50 anos, - mas se diverte muito. $\mathrm{O}$ sacrifício é grande, nos últimos dias da festa às vezes fica sem dormir ou então dorme num colchãozinho no fundo em meio a muito barulho. Não dá tempo de passear, de ir nos eventos como: Desfile de Carro de Boi, procissão da madrugada, show da Banda Inclusiva do Luar, na Vila S. J. Bento Cattolengo ou nas novenas, todavia sente que está participando, virou uma tradição. Vem sabendo que pode até levar prejuízo, mas só de vir já sente que uma coisa ficou em seu coração. "O coração precisa de alegria", diz.

Cena 3 - O helicóptero da Polícia militar sobrevoa a Igreja Nova num voo rasante e administrado. O círculo urrante em tons repetidos chama a atenção de todos. Um bêbado expressa: “o que que esses macacos tá querendo, tá procurano bandido ou quer aparecer pru povo. Saí prá lá deixa o povo rezá, seu macaco”.

Cena 4 - O Governo do Estado monta uma enorme barraca que oferece gratuitamente café, pão e leite para os caminhantes que saem de Goiânia e vão - a pé - na rodovia dos romeiros que, dessa vez, num curto espaço de tempo foi reformada com novo asfaltamento, passarelas e pistas para a caminhada das pessoas entre Goiânia e Trindade, de maneira a propiciar maior segurança para os romeiros. Muitos jovens que fazem a caminhada em grupo, vestidos com camisetas estilizadas, repetem a cena anualmente, desfilam-se, beijam, namoram, praticam azarações. A barraca do governo não impede que outros barraqueiros se instalem para vender água de coco, pastéis, água mineral no pontilhado do caminho 
organizado por imensos painéis da via Sacra, alvo de fotografias que, posteriormente, são postadas em redes sociais como o Facebook.

Cena 5 - Instalam-se no pátio da Igreja Nova várias centrais de TVs e de rádios. A fila do achado e perdido é a maior. Os locutores processam a programação ao vivo defronte ao círculo dos rezadores. Muitos romeiros tiram fotografias frente às cabines, indiretamente midiatizam a sua presença na Romaria. Outros ficam olhando como o expediente de trabalho da mídia funciona.

Todas essas cenas, certamente limitadas face ao grande, diverso e portentoso peso demográfico da Festa-Romaria de Trindade, expressam e sinalizam sentidos e significações do evento: trata-se de um conjunto de acontecimentos culturais, de enovelamento de símbolos, de confirmação da força de tradições, de sua reinvenção, de sua hibridez e, especialmente de uma disputa de apropriação que tem a presença de atores hegemônicos como o Estado, a Mídia, a polícia, a gestão local. E outros sujeitos como camponeses e fazendeiros tradicionais; gente da classe média urbana; trabalhadores do terciário de barraquinhas ${ }^{5}$; evangélicos, espíritas, artistas, intelectuais e estudantes.

A inesgotável multiplicidade de rostos, todavia não escapa de criar uma confluência: é essa diversidade que retrata as mudanças de Goiás. Poder-se-ia dizer: a Festa-Romaria de Trindade é igualmente um rosto de Goiás. Em função disso, o problema que ampara as reflexões que virão a seguir: como enxergar na apropriação diversa da festa/romaria de Trindade as mudanças do/no território goiano?

Um pressuposto norteará as reflexões: ainda que a Festa-Romaria de Trindade apresente sinais de mudanças gigantescas da inserção do território goiano a partir da cultura de seu povo no país e no mundo, os componentes singulares que sustentam a sua prática permanecem tecendo a sua primazia e a sua primordialidade. Isso permite considerar que os componentes simbólicos de um povo negociam os tempos e as práticas sem, contudo, desaparecer.

É exatamente essa consideração que exige a perícia da pesquisa, a acuidade metodológica, uma vez que nos vãos simbólicos, nas passagens sutis, nas menções quase invisíveis encontram-se os dispositivos de sentidos em negociação. Ao dizer assim, defende-

\footnotetext{
${ }^{5}$ Entende-se como terciário de barraquinha a situação pela qual, trabalhadores avulsos de vários lugares do país saem de suas cidades e seguem as festas para fazer o exercício de venda de bijuterias, santos, roupas, sapatos etc. Esses trabalhadores não possuem nenhum vínculo formal no mundo organizado do trabalho. São, portanto, trabalhadores que também desenvolvem serviços a partir das barraquinhas que seguem as festas.
} 
se que qualquer prática cultural tende a se estabelecer num plano tenso conforme é a vida de qualquer sujeito humano: abre-se para não esgotar; permanece para não explodir. No negócio as permanências são modificadas; as modificações se assentam nos símbolos que permanecem.

Para a realização desta pesquisa desenvolveu-se rotas de acompanhamento de vários eventos da Festa-Romaria de Trindade. Dedicou-se mais atenção no Evento de acolhida da Vila São José Bento Cattolengo; na procissão da madrugada; no desfile de Carro de boi; no modo como os festeiros circulam diante das cabines da mídia; na novena; nas barraquinhas e na caminhada da Avenida do Romeiro. Baseada em procedimentos metodológicos qualitativos como a observação participante, a pesquisa procedeu-se também de entrevistas e conversas livres com donas de casa, vendedores ambulantes, barraqueiros, devotos e jovens urbanos de Goiânia que se encontravam em almoços de família.

Além de componentes como o turismo religioso e as manifestações culturais do catolicismo - orações, terços, peregrinação, procissões, queima de velas, oferendas, folias de reis, missas e imagens de santos - que transitam a apropriação simbólica dos espaços da FestaRomaria, é perceptível as relações precarizadas de trabalho, as oportunidades de negócios e os pactos de poder entre o Estado, a Mídia e a Igreja. Ambos os aspectos se aglutinam entre fé profana e sacra ao mesmo tempo, na maior Festa-Romaria de Goiás e uma das maiores peregrinações do país.

\section{PAISAGENS TURÍSTICAS DE TRINDADE/GO: A RELIGIOSIDADE COMO ATRATIVO TURÍSTICO E OPORTUNIDADE DE NEGÓCIOS}

Trindade (mapa 1), município goiano com aproximadamente 121 mil habitantes, localizado a menos de $20 \mathrm{~km}$ da capital do estado de Goiás - Goiânia - atrai milhões de peregrinos anualmente, envolvidos nas práticas do turismo religioso. O ápice dessa mobilidade de turistas, de fiéis e de peregrinos, acontece no contexto da Festa-Romaria em torno do Santuário Basílica do Divino Pai Eterno, por onde passaram cerca de 3 milhões de pessoas, em apenas dez dias do evento entre o final de junho e início de julho de cada ano. 
Mapa 1: Localização geográfica do município de Trindade (GO).

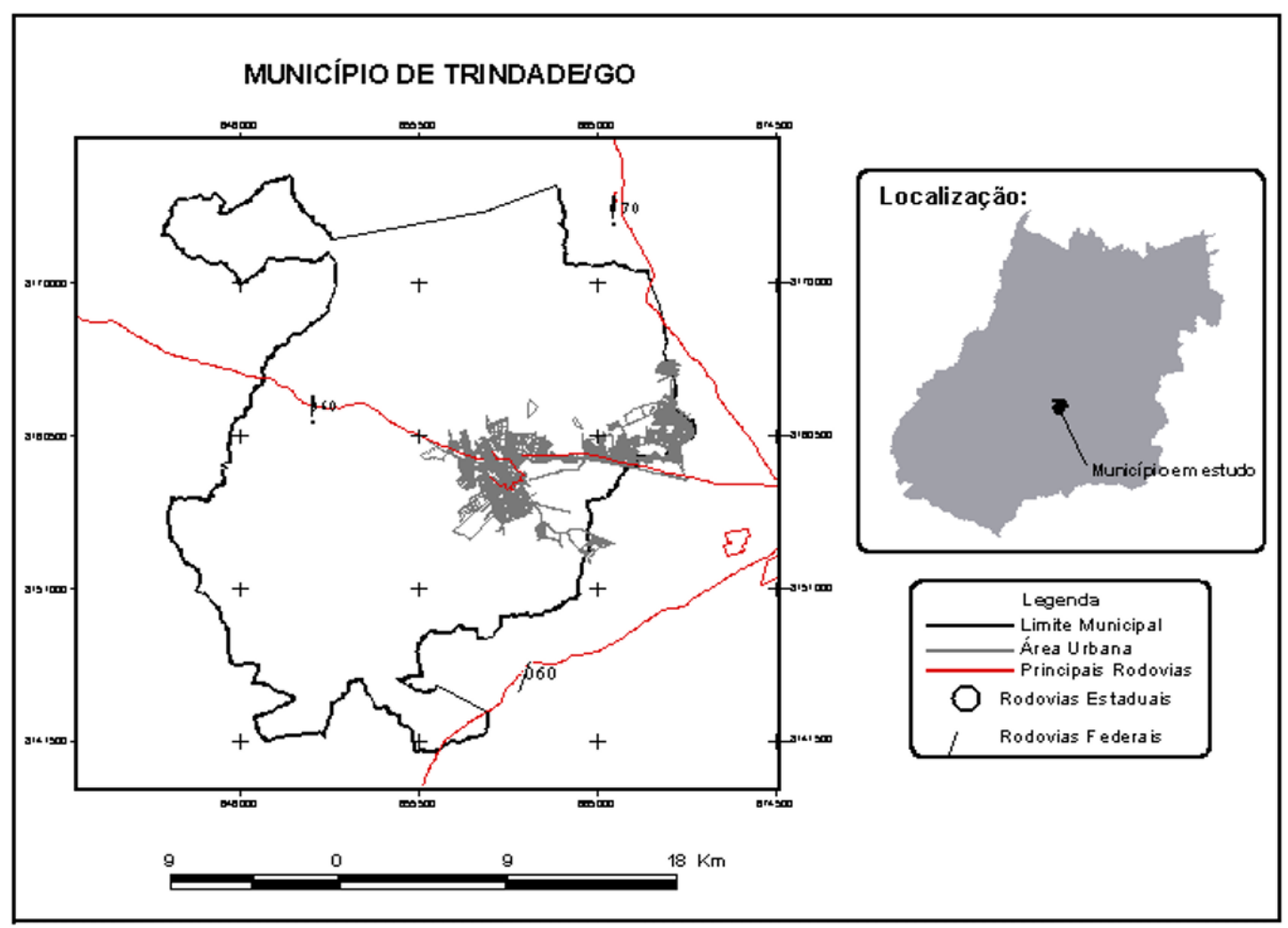

Fonte: RODRIGUES, W. J., 2018.

A Festa-Romaria de Trindade revela símbolos da cultura sertaneja goiana. Pode-se dizer também que anuncia "o mundo humano na concretude histórica em que os espaços e os lugares são, cotidianamente, construídos e vivenciados" (CHAVEIRO, 2008, p. 77). Esses aspectos são grafados na paisagem, entendida como uma construção histórica, produto da apropriação e da transformação do ambiente em cultura, atribuindo-lhe diferentes significados. Como afirma Almeida (2008, p. 47) "a paisagem é uma complexidade multiforme de realidades, de valores, de gestos e de vividos coexistentes". Nas festas populares de caráter religioso como acontece em Trindade, as paisagens são reveladoras das manifestações materiais e imateriais da cultura, neste caso, com forte expressão do catolicismo.

Outro componente que se destaca nestas festas é o alto investimento no turismo, instrumento de forças sociais, políticas e econômicas. O turismo religioso, segundo Pinto (2011, p.24), "pode ser sinteticamente considerado como um segmento de mercado diferente de todos os outros, tendo como motivação principal a fé”. Segundo Lopes (2006, p. 17) a motivação religiosa está entre os principais motivos de viagens turísticas e 
[...] tem levado milhões de pessoas a se movimentarem num mundo sagrado, estas viagens envolvem o percurso de longas distâncias e por vários meios de transportes, podendo ser executadas de forma voluntaria, cuja motivação principal é religiosa, são chamadas, em geral, de peregrinações e apresentam uma quebra de rotina diária dos participantes que deixam para traz o mundo profano para aproximar-se do sagrado (LOPES, 2006, p. 17)

Nos diferentes quadrantes do mundo, a fé tem feito com que milhões de pessoas se desloquem espacialmente na busca por locais onde importantes eventos religiosos aconteceram. Muitas pessoas que visitam esses locais, "pagam promessas" e acreditam que eles são "fontes" de milagres. Monumentos suntuosos são erguidos pelos diferentes grupos religiosos, que pela sua beleza arquitetônica e riqueza histórica, também motivam a realização de visitação turística. Templos budistas, mesquitas, basílicas, entre outros tipos de infraestruturas religiosas atraem milhões de peregrinos.

Em Trindade/GO, o Santuário Basílica do Divino Pai Eterno (Figura 1) é um dos exemplos de locais por onde passam fiéis manifestantes da fé católica de distintas partes do Brasil em todos os meses do ano. Além disso, transformam a movimentação econômica local, seja através dos supermercados, feiras, bares, pousadas ou hotéis.

Figura 1: Santuário Basílica do Divino Pai Eterno, em Trindade - GO. Em primeiro plano, infraestrutura sendo montada para a missa campal, que marca o encerramento da maior festa religiosa de Goiás.

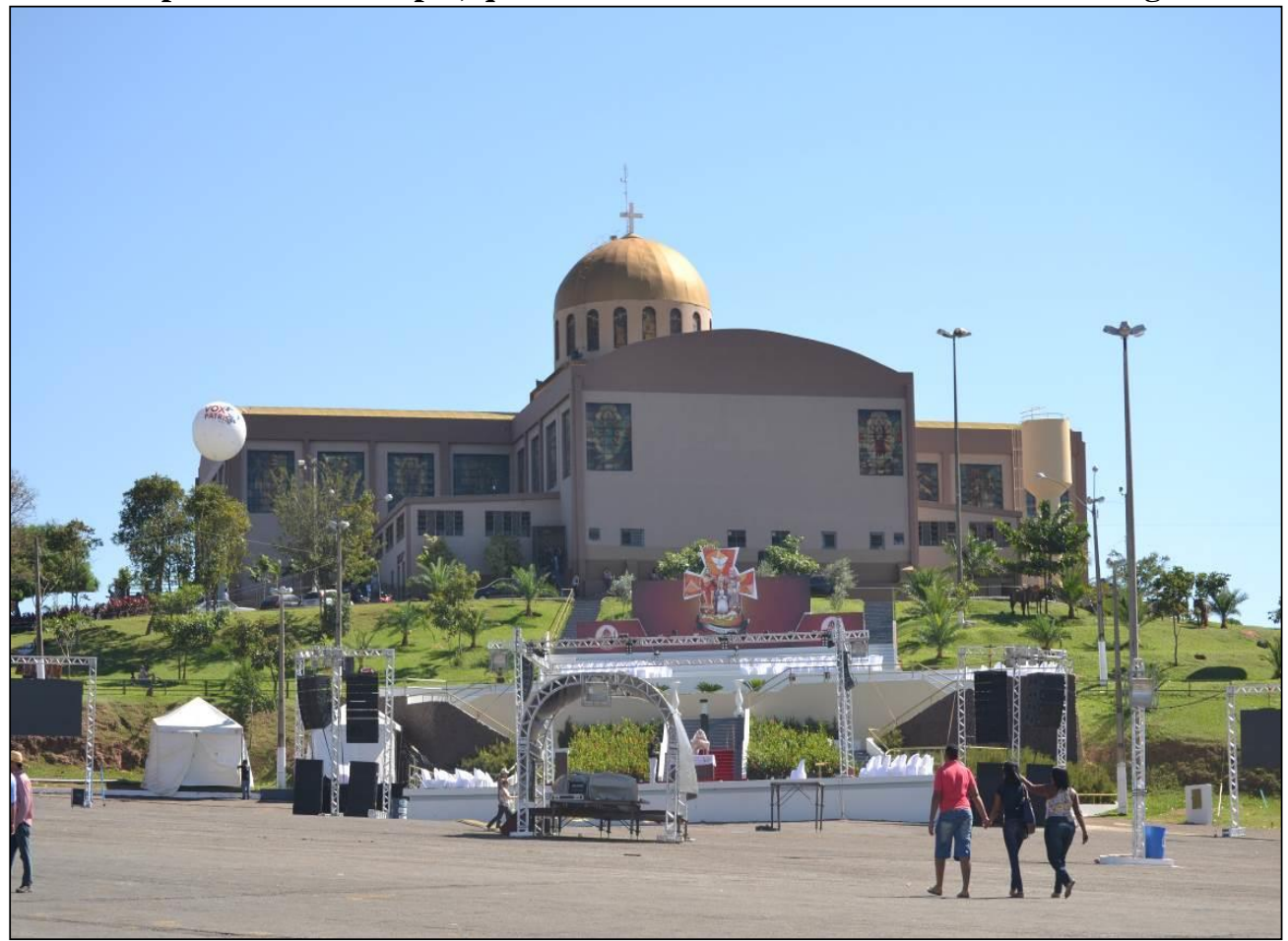

Fonte: Pesquisa de campo realizada na Festa-Romaria de Trindade, 2013. 
SOCIEDADE E

TERRITÓRIO
CHAVEIRO, Eguimar Felício

GONÇALVES, Ricardo Junior de Assis Fernandes

AZEVEDO, Helsio Amiro Motany de Albuquerque

Autor: Azevedo, 2013.

No Santuário Basílica do Divino Pai Eterno (Figura1) e nos vários espaços da FestaRomaria passam velhos, jovens, homens e mulheres de diferentes classes sociais. Chegam ao Santuário rezando terços, cansados, porém sorrindo e abraçados com amigos ou familiares, outros emocionados ou agradecendo pelas graças que acreditam terem recebidos. "Muitos rostos, cada um com uma história invisível”, diz um dos integrantes da pesquisa de campo. Alguns voltam para o local de origem - missão cumprida - outros ficam na festa, participam das missas, do desfile dos carreiros, das procissões e visitam a Vila São Cottolengo, choram no show da Banda Inclusiva ao Luar ou dançam abraçados e de mãos dadas com os deficientes.

Também há aqueles que juntaram dinheiro e então é o momento de fazer as compras nas barraquinhas - calça jeans por $\mathrm{R} \$ 20,00$, cinco pares de meias por $\mathrm{R} \$ 10,00$, camisa importada por $\mathrm{R} \$ 35,00$, bijuterias e aparelhos eletrônicos Made in China (celulares que filmam e tiram fotos, pen drive, fones de ouvido, rádios, microfone, gravador etc.), bermuda, tênis em promoção no fim da festa - "é preciso aguardar e não gastar todo o dinheiro", diz um entrevistado. Por outro lado, nos interstícios, alguns apostam nas barracas de jogos (tiro ao alvo, bingo, argolas etc.), dançam forró nos shows sertanejos, praticam mendicância, consomem drogas e bebidas alcoólicas, se embriagam ou se prostituem, e quando o dia amanhece rogam ao Divino Pai Eterno que perdoe os exageros da noite passada.

A organização dos territórios religiosos, do trabalho e dos negócios na Festa-Romaria de Trindade/GO, para atender o turismo, requer um grande aparato que engloba agentes diversos (o governo, os empresários, a mídia, a própria denominação religiosa, a comunidade local praticante ou não, entre outros). Criam-se assim dinâmicas espaciais motivadas pelo turismo religioso, que contribui para a modificação/transformação dos lugares e das paisagens da cidade. Há investimentos em estruturas de hotéis, restaurantes, sistemas de comunicação e rodovias para responder aos fluxos de romeiros.

As parcerias e os pactos de poder - velados ou não - entre o Estado, a Mídia, a Igreja e o Governo Municipal também manifestam interesses políticos e econômicos expostos em obras de infraestrutura, discursos e outdoors, em torno da composição dos territórios que compõem a Festa-Romaria. Para Chaveiro (2008), a sua força demográfica, ao mobilizar a mídia, sujeitos de negócios e o Estado a golpearem um aproveitamento simbólico, político e 
social do evento. Além disso, fazem dele uma constelação de transformações socioespaciais de Goiás.

Nos dez dias da Festa-Romaria de Trindade as paisagens da Rodovia dos Romeiros, por exemplo, se transformam, seja pelo movimento dos fiéis nas margens da via dos romeiros ou pelas barracas instaladas para comercialização de lanches, água mineral e água de coco. Outras instalações também servem para dar suporte às pessoas no decurso da caminhada, além de informações sobre as missas realizadas no Santuário. A Organização das Voluntárias de Goiás (OVG) propiciou a criação Centro de Apoio aos Romeiros, que forneceu alimentação - leite, café, chá, suco, refrigerante, bolachas, pão recheado com mortadela, manteiga e mussarela e água potável. Além disso, os romeiros contaram com atendimentos de saúde prestado por enfermeiras e médico para eventuais casos de emergência. No local, também é erguido um posto de comando da Polícia Militar com uma ambulância e uma viatura de resgate do Corpo de Bombeiros de prontidão 24 horas.

No trajeto de $18 \mathrm{~km}$ entre Goiânia e Trindade, algumas pessoas caminham reunidas com amigos, namorado(a), marido, esposa e filhos. Agradecem pela saúde, relataram curas milagrosas e promessas. Uma entrevistada que empurrava uma cadeira de rodas com o filho deficiente disse: "eu venho de Goiânia e é o segundo ano que eu faço essa caminhada de fé e orações, já recebi muitas bênçãos do Divino Pai Eterno".

De forma semelhante, esses aspectos também foram apreendidos numa pesquisa realizada por Chaveiro (2008). O autor menciona elementos que compõem as impressões sobre a festa e mobilidade de fiéis e peregrinos na Rodovia dos Romeiros.

\begin{abstract}
A primeira impressão extraída do contato com a atividade festiva foi o peso demográfico. Uma cortina interminável de pessoas andava de Goiânia e Trindade cumprindo a missão de romeiros viajantes. Jovens andavam de maneira serelepe, geralmente trocando risos, apropriando-se da caminhada mediante o estatuto juvenil; adultos vestiam camisetas estilizadas; algumas mulheres "pagavam votos" conduzindo seus filhos de um a dois anos em carrinhos; alguns idosos apresentam mais dificuldades. E havia também grupos de pessoas que andavam rezando terços. [...] A caminhada ia se colocando como um rito híbrido, ora se efetivando como cena da cultura juvenil, ora como momento de espiritualização de cristãos rumo à “terra prometida": a cidade do Divino Pai Eterno (CHAVEIRO, 2008, p. 79-80).
\end{abstract}

Em Trindade, as diferentes áreas do espaço urbano são afetadas no contexto da FestaRomaria. Grupos, sujeitos e instituições despertam diversas possibilidades de usos e apropriação da cidade. Assim, surgem oportunidades de negócios para os residentes locais, viajantes, artistas de rua, trabalhadores informais e empresas que encontram nesses eventos 
religiosos e culturais, momentos ímpares para incrementar vendas de diversos produtos, principalmente alimentos e bebidas (frutas, salgados, pastéis, espetinhos, latas de cervejas, água mineral etc.), além de prestação de determinados tipos serviços (como aluguel de calçadas, quartos, banheiros, lotes para barracas ou estacionamentos), (Figura 2). Isto é, criase uma nova dinâmica espacial e econômica.

Figura 2: Oferta de serviços como banhos e aluguel de calçadas, que são comuns no contexto da FestaRomaria de Trindade e constituem como renda complementar para muitos residentes locais.

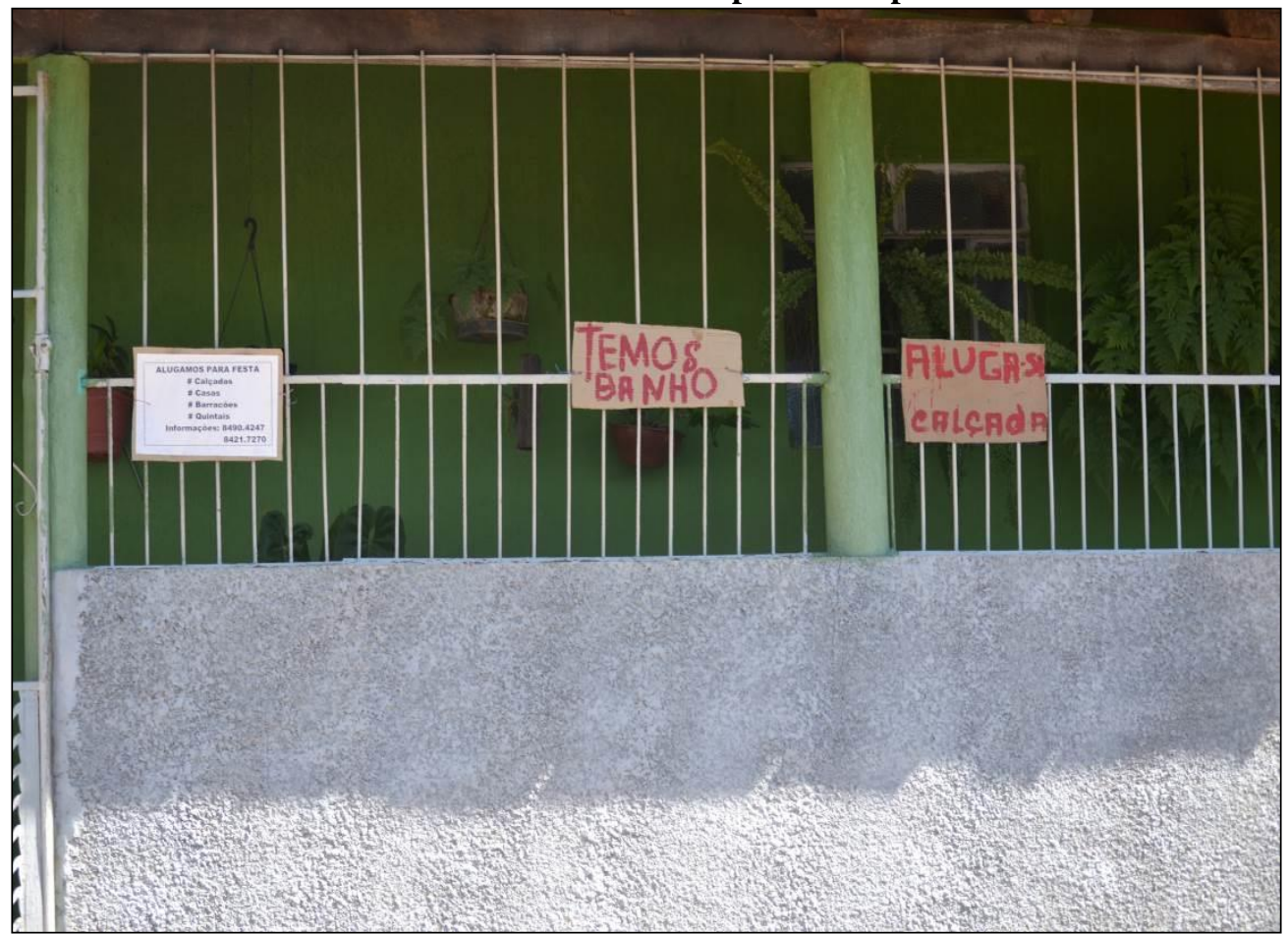

Fonte: Pesquisa de campo realizada na festa/romaria de Trindade, 2013.

Autor: Gonçalves, 2013.

Este artigo, ao abordar e retratar a multiplicidade dos espaços apropriados pela Festa do Divino Pai Eterno de Trindade (ou Festa dos Romeiros) e denominada por Murilo (2013) de Romaria dos milhões, contribui para mostrar que este município se encontra inserido numa dinâmica socioeconômica motivada pelo turismo religioso e que produz paisagens diversas.

Para o setor do turismo, a tramas que se territorializaram em Trindade são atrativas, pois nela residia/reside à motivação que mobiliza os romeiros/turistas/excursionistas que se deslocavam/deslocam a este município no sentido de exaltar a religiosidade a partir de momentos de profundo "contato" com o sagrado. De acordo com a Secretaria de Planeamento do Estado de Goiás-SEPLAN (2005, p. 81) 
[...] a festa do Divino Pai Eterno leva milhares de pessoas a Trindade, pagando promessa por bênção recebida, movendo pessoas a percorrerem longas distâncias até o Santuário de Trindade. A história da Romaria de Trindade começa por volta de 1840, quando um casal encontra junto ao córrego Barro Preto um medalhão de barro que representa a Santíssima Trindade coroando Nossa Senhora. Neste local, hoje está localizada a Igreja Matriz. Trindade, a "Terra do Pai Eterno" além do Santuário do Divino Pai Eterno, que atrai milhares de turistas, dispõe da rodovia dos Romeiros onde é realizada a Caminhada da Fé, do Carreiródromo, onde ocorre o maior desfile de carros de bois do mundo. Outro grande atrativo turístico constitui a Igreja do Santíssimo Redentor que abriga os despojos do missionário redentorista Padre Pelágio. A Avenida Constantino Xavier que abriga 15 estações da via sacra constitui um novo caminho sacro ligando o Santuário do Divino Pai Eterno à Igreja do Santíssimo Rendentor.

Os milagres que compõem o imaginário religioso e são anunciados na Festa-Romaria fizeram/fazem com que outros povos de outras regiões do Brasil e do planeta se deslocassem/desloquem para visitar o local dos acontecimentos. No passado muitas famílias que se reuniam neste local para as celebrações se organizavam em acampamentos montados de forma precária. Nos dias atuais (2015) e em função dos novos padrões de vida e sociabilidades urbanas da sociedade houve a necessidade de aprimorar as infraestruturas no sentido de atender ao número de romeiros cada vez mais crescente, que anualmente, antes/durante e/ou depois da festa, visitam este município. As transformações de hábitos e espaços são evidenciadas pela Assessoria de Imprensa do Santuário Basílica (2012, p. 1) ao abordar que

\begin{abstract}
Os hábitos rurais deram espaço para os avanços tecnológicos e todo o conforto que o pensamento moderno é capaz de assegurar. Algumas das antigas e importantes estruturas já nem existem mais, contudo, grandes construções foram edificadas e dividem atenção dos turistas, juntamente com monumentos históricos tombados como patrimônio de Goiás. Em paralelo às mudanças sociais e econômicas, o turismo religioso tem se fortalecido a cada ano, colocando Trindade na principal rota turística do Centro-Oeste, além de contribuir para o desenvolvimento local. O Santuário Basílica tem recebido cerca de 3.500 novos visitantes por semana, uma média semanal de 70 excursões. Somente na Romaria 2012, durante dez dias, cerca de 2,6 milhões de pessoas passaram por Trindade. Esse número representa quase um milhão a mais do que o registrado há cinco anos, em 2007, quando foram registrados 1,7 milhão de visitantes. Desde 2008, com a criação do Projeto de Planejamento Estratégico do Turismo Religioso de Trindade, estão sendo desenvolvidas ações para melhorias em hospedagem e alimentação. Atualmente são mais de 100 hotéis e pousadas e cerca de 50 restaurantes, sendo que tem aumentado consideravelmente o número de empreendimentos nos últimos anos.
\end{abstract}

As informações e os números ilustrados acima demonstram a expressão do evento e dos impactos causados por este, principalmente, nos setores do turismo e do comércio. Neste ano (2013), por exemplo, em parceria com a Secretaria Municipal de Turismo, o Serviço de Apoio às Micro e Pequenas Empresas (SEBRAE GOIÁS), através do Projeto Circuito 
Turístico Fé no Coração do Brasil, treinou 20 funcionários do Centro de Atendimento ao Turista (CAT), qualificando-os para o atendimento aos visitantes e aplicação de uma pesquisa para conhecer o perfil de quem vai a Trindade durante a Festa do Divino Pai Eterno, que contribuiram para ajudar nos planejamentos para a festa/romaria de 2014 (SABINO, 2013).

Em função do aumento numeroso de devotos/turistas, as estruturas da igreja neste município, um novo Santuário ${ }^{6}$ com maior espaço para atender os fiéis está em construção. Quando finalizado, esse projeto expressará uma nova dinâmica na paisagem de Trindade/GO, pois a nova Basílica do Divino Pai Eterno implicará na transformação de roteiros, na criação de novos serviços e infraestruturas nas proximidades. Parte do comércio que se verifica nesta festa/romaria poderá migrar e antigos "beneficiários" de negócios, essencialmente, residentes locais que alugam calcadas poderão perder clientes e oportunidades de lucros nos períodos festivos. Portanto, é a Festa-Romaria mudando e/ou transformando as paisagens e produzindo novas dinâmicas que consequentemente irão se expressar desdobramentos no setor turístico, na organização do território e nas diferentes manifestações do trabalho.

\section{AS MANIFESTAÇÕES DO TRABALHO NA FESTA-ROMARIA DE TRINDADE}

As pesquisas de campo realizadas desde 2013 na Festa-Romaria de Trindade permitiram lançar diferentes olhares sobre a forma como os territórios e o trabalho se (re)organiza para dar respostas a demanda turísta e a mobilidade de fiéis, que também consomem e transformam a movimentação econômica local. Como demonstrado, emergem múltiplas oportunidades de apropriações dos espaços da cidade no contexto da festa, mas, que não se reduz a ela. É fato que o turismo religioso em Trindade extrapola os meses de junho e junho. No entanto, a Festa do Divino Pai Eterno modifica a dinâmica da população local e as estratégias da gestão municipal. No ano de 2013, por exemplo, a prefeitura colocou em torno de dois mil funcionários para atuar durante a festa, seja no âmbito da vigilância sanitária, meio ambiente, saúde, apoio aos romeiros etc. (MURILO, 2013).

\footnotetext{
6 "Se a atual Basílica do Pai Eterno tem cerca de 2,5 mil lugares, apenas a capela principal do novo santuário tem previsão de instalação, quando concluída, de aproximadamente 6 mil assentos. No espaço interno da igreja, deverá caber um público total de até 13 mil pessoas, segundo o engenheiro civil Kléssio Gonçalves. Na praça, que representa toda a estrutura do complexo da nova Basílica do Pai Eterno, a expectativa é de que a área construída consiga receber até 300 mil pessoas”. (Jornal Opção, 2017, p. 01).

Nos espaços da festa/romaria outdoors chamavam a atenção dos fiéis e turistas com a frase: "Vamos juntos construir a casa do pai".
} 
Nos últimos anos, diante das ações do poder público, muitas vezes orientado pela Igreja, as atividades de comércio e os espaços e estruturas da Festa-Romaria sofreram modificações para atender ao turismo religioso. Maia e Coelho (2006, p. 113) numa pesquisa realizada em meados da década passada registraram esses aspectos ainda em curso.

No que se refere às atividades de comércio, notamos que estas foram disciplinadas pelo poder público, orientado pela igreja. Desse modo, condenou-se e "proibiu-se" a venda de bebidas alcoólicas nas barraquinhas instaladas ao longo da Rodovia dos Romeiros, que liga Goiânia à Trindade, a fim de manter a piedade no deslocamento. Dentro da cidade, antes de 2001, as barracas alocadas nas áreas públicas eram construídas com estrutura de madeira, ou bambu, e cobertas com folhas de palmeiras e lonas de panos ou plásticas, trazendo para o núcleo urbano de Trindade resquícios tradicionais de uma paisagem rural. Não havia também tanta preocupação com o cadastramento e fornecimento de autorização para os ambulantes, "informais" em relação à festa, bem como para os pedintes. Desde aquele ano, as barracas no espaço público são montadas com estrutura metálica, cobertas com um toldo azul e/ou branco, contendo o distintivo do Governo do Estado de Goiás e da Prefeitura de Trindade. Estas alterações, juntamente com outras melhorias (instalação de sanitários químicos, fornecimento de água tratada pela Saneago - Saneamento de Goiás S/A - e uniformização dos mendigos), têm agradado os comerciantes. Dos 54 comerciantes entrevistados em 2001, 59\% aprovaram as mudanças ocorridas naquele ano.

As transformações destacadas por Maia e Coelho (2006) possuem desdobramentos na organização dos lugares e paisagens da festa, sejam religiosos, de consumo ou de diversão. Além disso, um dos elementos que se destacaram nas pesquisas de campo foram as manifestações do trabalho no período da Festa-Romaria. Nos restaurantes, padarias e hóteis criam-se novos empregos temporários, segurança policial e corpo de bombeiros são reforçados e os serviços de taxi são ampliados. Erguem-se barracas nas calçadas, varandas, lotes, garagens, canteiros e por praticamente todas as ruas próximas ao Santuário Basílica do Divino Pai Eterno (Figura 3). Comerciantes, viajantes e vendedores ambulantes dormem nas próprias barracas, enfrentando condições precárias no período da festa. 
Figura 3: Barracas de bijuterias, itens religiosos, lanches e roupas nas ruas da Festa/Romaria de Trindade.

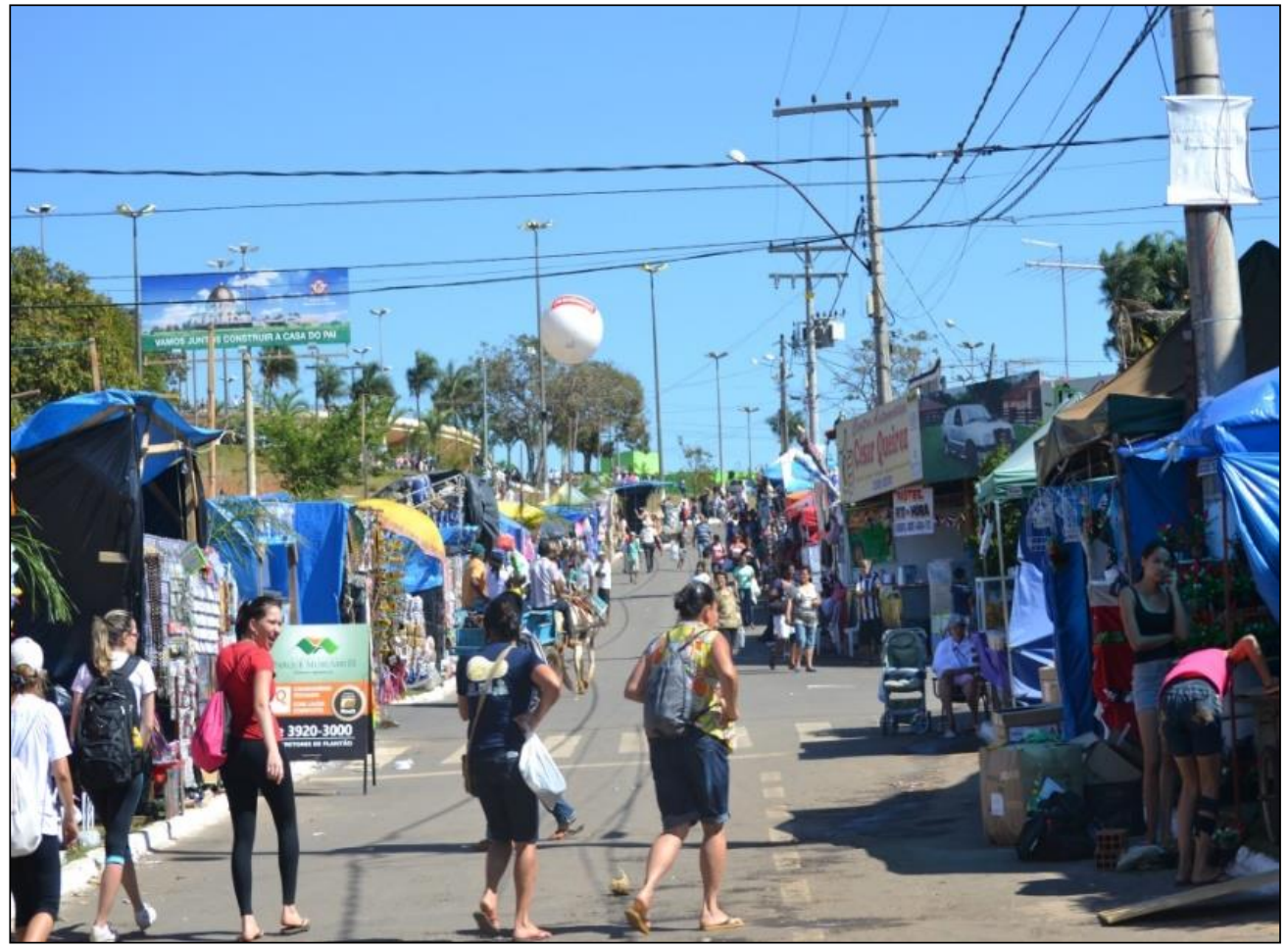

Fonte: Pesquisa de campo realizada na Festa-Romaria de Trindade, 2013.

Autor: Gonçalves, 2013.

Ao perguntar o dono de uma barriquinha de itens religiosos sobre a expectativa de venda, disse que a festa é a melhor época do ano para ampliar os lucros. Seu estoque de réplicas da Santíssima Trindade foi triplicado diante da procura gerada pelo aumento do número de romeiros que passaram em sua barraca. Ainda, o proprietário de uma barraquinha que comercializa pastéis, sucos e refrigerantes precisou contratar quatro funcionários. Nos últimos dias festivos atravessaram a noite atendendo a crescente quantia de romeiros que chegavam à cidade.

Por essas ruas, passam fiéis de diferentes regiões de Goiás e do Brasil, que recorrem principalmente as barraquinhas de itens religiosos para comprar e levar de presente aos amigos e familiares uma lembrança da Festa do Divino Pai Eterno. Nos meandros desse processo o trabalho informal e temporário também se recria. ${ }^{7} \mathrm{O}$ trabalho informal é um dos

\footnotetext{
${ }^{7}$ Conforme Jakobsen (2001, p. 13) “O termo "setor informal” foi cunhado pela Organização Internacional do Trabalho (OIT) e utilizado pela primeira vez nos relatórios sobre Gana e Quênia, elaborados no âmbito do Programa Mundial de Emprego, em 1972. Uma das principais conclusões alcançadas nestes relatórios foi que o problema social mais importante naqueles países não era o desemprego, mas sim a existência de um grande número de "trabalhadores pobres", ocupados em produzir bens e serviços sem que suas atividades estivessem reconhecidas, registradas, protegidas ou regulamentadas pelas autoridades públicas".
} 
aspectos que contribuem para se entender a crescente precarização e precariedade dos trabalhadores na atualidade, diante das reconfigurações do mundo do trabalho. No entando, segundo Tavares (2002, p. 49) “o trabalho informal não é um fenômeno novo no mundo do trabalho, especialmente no Brasil, onde a dualidade e a heterogeneidade do mercado de trabalho são problemas histórico-estruturais."

Para Antunes (2009), as mutações no mundo do trabalho e das diferentes formas de explicitação do ser social que trabalha (assalariado, autônomo, terceirizado, domiciliar, informal, precarizado e cooperado) revelam uma classe trabalhadora mais heterogênea e mais complexificada, dividida entre trabalhadores qualificados desqualificados, do mercado formal e informal, jovens e velhos, homens e mulheres, estáveis e precários, imigrantes e nacionais, brancos e negros etc, sem falar nas divisões que decorrem da inserção diferenciada dos países e de seus trabalhadores na nova divisão internacional do trabalho.

As transformações no mundo do trabalho excluem contingentes de jovens e idosos do mercado de trabalho formal com carteira assinada e outros benefícios. Nos centros urbanos, as condições de pobreza e desemprego expressam os desdobramentos desiguais da reprodução capitalista. $^{8}$ Neste sentido, a informalidade e empregos temporários são elementos que explicitam a crescente precarização dos trabalhadores em distintas áreas. Para Coelho (2003, p. 244) “As festas religiosas e os dias de descanso da semana, do mês ou do ano são temposespaços de comércio periódico desde os tempos antigos.” Por isso, a pergunta que se fez na pesquisa foi: é possível perceber essas manifestações do trabalho na festa/romaria de Trindade? O que os rostos, ações e práticas dos trabalhadores revelam?

Ao caminhar nas ruas da cidade e através da observação participante na Festa/Romaria, essas reflexões tornaram-se claras, anunciando respostas para esses questionamentos. São comerciantes ambulantes que carregam caixas de isopor, tabuleiros e carrinhos de picolé. Outros vendem bebidas alcoolicas ilegalmente e esperam lucrar e acumular um dinheiro extra até o final da festa, que ajudará na gestão dos gastos no decorrer do ano. Além disso, colares, óculos escuro, aparelhos eletrônicos, água mineral, refrigerantes, churrasquinhos e salgados são oferecidos ao público. Mesmo perante as ações de controle e fiscalização, as práticas de comércio e trabalho informal se resignificam e diversificam-se nos espaços e tempos festivos.

\footnotetext{
${ }^{8}$ No entanto, Maia (1999, p. 144) diz que "a economia considerada informal não é constituída só por pessoas excluídas do sistema de produção capitalista vigente, mas também por pessoas que optam pelas vantagens da produção independente, como a jornada de trabalho flexível e a organização do negócio próprio".
} 
Entre os homens, mulheres, velhos e jovens que transitam na informalidade, a criatividade, o improviso e a alegria são gestos que chamam a atenção dos consumidores. $\mathrm{Na}$ face dos vendedores ambulantes, as rugas e a pele queimada pelo sol imprimem marcas da vida e do trabalho duro. Um vendedor de picolé disse que antes morava na roça e sempre vinha na festa de Trindade de carro de boi, agora vive na cidade, é aposentado, mas, aproveita o momento para faturar uma renda complementar. Enquanto empurra o carrinho, na sua cabeça e na de outros romeiros que passam próximos a ele, o chapéu não só protege do sol, mas, revela símbolos de sociabilidades camponesas e do sertanejo goiano (Figura 4).

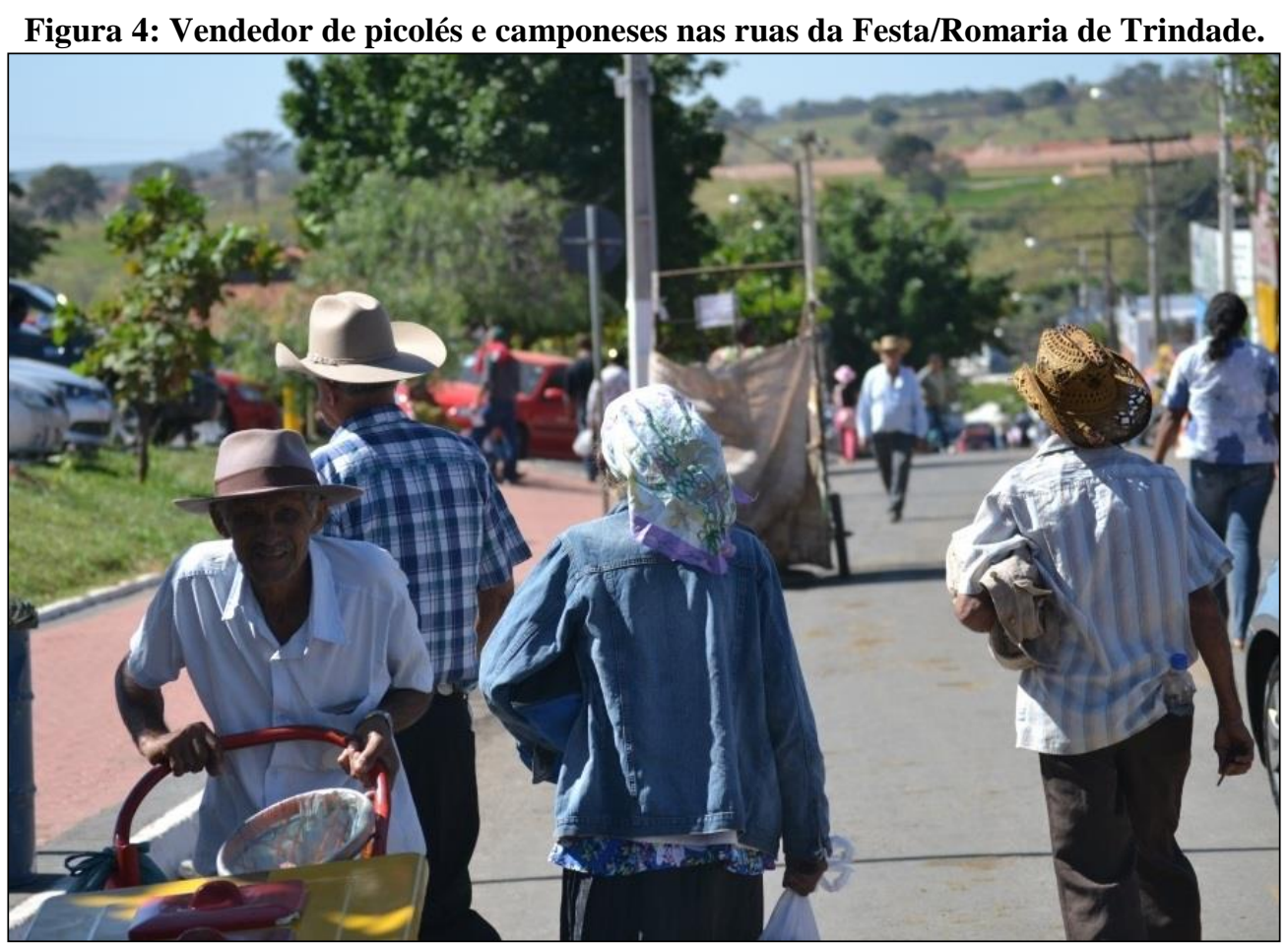

Fonte: Pesquisa de campo realizada na festa/romaria de Trindade, 2013. Autor: Gonçalves, 2013.

Outra manifestação do trabalho nos espaços da Festa-Romaria de Trindade e que despertou a atenção dos pesquisadores foram os catadores de lixo reciclável. Nas observações diretas no contexto da festa em 2013 percebeu-se que esse tipo de coleta, apesar de envolver distintos sujeitos de maneira autônoma no entorno do Santuário Basílica, Igreja Matriz, nas praças e nas ruas, também contou com a intervenção do Sebrae Goiás, que desenvolveu o Plano de Gerenciamento de Resíduos Sólidos, aplicado pela Secretaria Municipal de Meio Ambiente e Recursos Hídricos de Trindade (SEMMARH). Conforme Sabino (2013), catadores integrantes de cooperativas parceiras da Prefeitura de Trindade foram treinados para 
execução do trabalho. Eles atuaram na Rodovia dos Romeiros (GO-060) e no carreiródromo. Recolheram garrafas pet, plásticos, latas, papéis e papelão. Em torno de 40 toneladas de lixo reciclável foram coletados durante a Festa do Divino Pai Eterno. ${ }^{9}$

Um trabalhador se esforça para puxar um carrinho onde reúne o lixo reciclável coletado nas ruas de Trindade. Essa imagem, fotografada por um dos pesquisadores (Figura 5), não se reduz aos espaços da festa, mas, também revela as desigualdades e contradições da sociedade de classe.

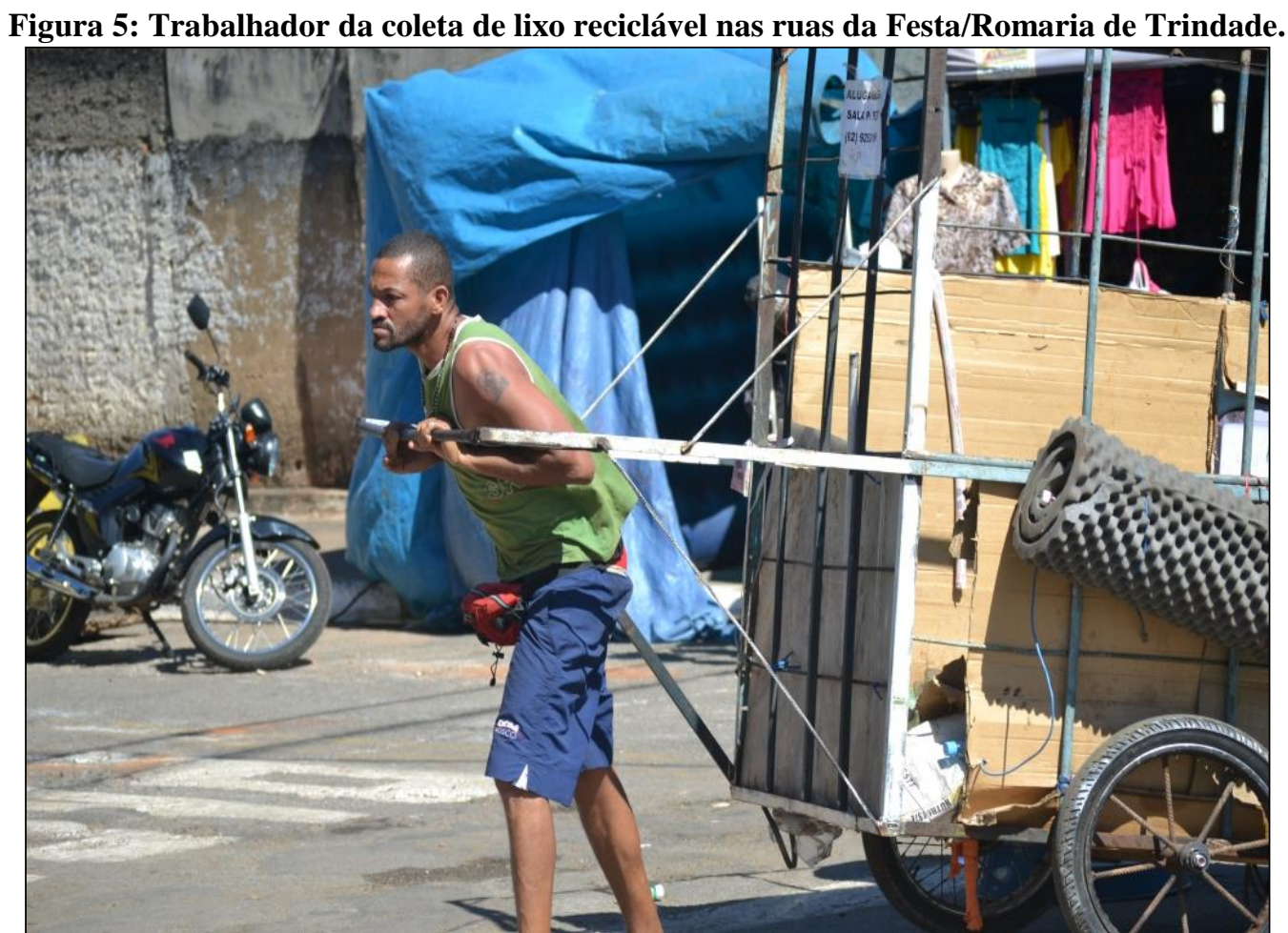

Fonte: Pesquisa de campo realizada na Festa-Romaria de Trindade, 2013.

Autor: Gonçalves, 2013.

Numa Festa-Romaria apropriada pela mídia e pelos discursos hegemônicos do Estado e da Igreja, e onde os gestos da fé católica e os símbolos da cultura goiana ganham força, os catadores de lixo reciclável testemunham as condições de precariedade do trabalho na festa, que não está dissociada dos interesses e estratégias da mesma sociedade capitalista que oprime e explora esses e outros trabalhadores.

\footnotetext{
${ }^{9}$ Sabino (2013, p. 1) também informa que “Além do lixo reciclável, os cocos também foram retirados das ruas, praças, avenidas e rodovia e levados para uma indústria de reciclagem em Aparecida de Goiânia (GO). O fruto será secado para retirada das fibras, que vão virar substrato para plantas."
} 
Contudo, o amalgama de símbolos, de relações, de sujeitos, de trocas e de ações configuram algo: convém ultrapassar a leitura economicista da festa/romaria como, no mesmo termo, deve-se incluir aportes do trabalho, do modo como os sujeitos sociais se diferenciam e se conflitam no regime festivo.

\section{CONSIDERAÇÕES FINAIS}

A pesquisa apresentada neste texto tomou como mote cenas, situações e imagens da Festa-Romaria de Trindade. Percebeu-se que o gradiente demográfico do evento abre-a para um conjunto de apropriações marcadas pelo turismo religioso, pela ação de atores hegemônicos como o Estado, a Mídia e o Mercado, como por atores diversos.

Enxergou-se também que o evento se abre a outros eventos, daí poder afirmar que a Festa-Romaria é um estuário de acolhidas simbólicas. Modernas tradições inventadas como o desfile de Carro de Boi, a antiga novena à noite ou mesmo a procissão da madrugada são mescladas, hibridizadas e recolocadas num patamar em que o catolicismo popular mostra estar vivo e o cristianismo midiático tem força espetacular.

Mais do que isso: cenas como jogos, lazer, forrós, pegação e outras atividades incluem os novos ethos da juventude urbana. E cenas como almoços familiares, rezas de terço nas barracas, procissões, cumprimento de votos mostram a força de permanência das tradições que ajudam a sustentar as mudanças. Transformações cindidas pelos atravessamentos da mundialização do capital, redes de comunicação, sociabilidades e práticas da vida urbana que configuram a Festa/Romaria. Ademais, na concomitância, o Evento expressa cenas, cores, saberes e símbolos do espaço agrário goiano.

Os negócios simbólicos ${ }^{10}$ de vendedores alegres e sofridos; a disposição dos caminhantes que tenta construir armações comunitárias e andam em grupo de Goiânia para Trindade; as estratégias de prostitutas e de pedintes; a ação da gestão local do espaço festivo;

\footnotetext{
${ }^{10}$ Negociação simbólica advém da compreensão de que a cultura ocorre sempre em tensão. O expediente tensionador da cultura refere-se especialmente a dois campos: a luta para manter tradições e, ao mesmo tempo, a abertura para assimilar novos produtos, objetos e gostos. Quase sempre a esfera de tradição se situa como plataforma de constituição da memória e a esfera da assimilação como possibilidade de vivência cultural no mundo dado. Perder as raízes culturais significa dispensar os esteios da memória. Deixar de assimilar os componentes da cultura que se coloca na vivência significa enrijecer-se. Entre o enrijecimento e a porosidade surge a negociação simbólica.
} 
a comoção causada pela fé e o desejo de participar de um evento com legitimidade midiática expressam o lugar de Goiás no mundo, a sua diversidade, suas metamorfoses.

Ruídos, sacolinhas de plástico, fila de beijação, lixo estampado nos vãos dos paralelepípedos, gritos e competição de vendedores instalam o sentido complexo da festa/romaria de Trindade. Mostram também que o ser humano, animal simbólico, cria o tempo no espaço, constrói e reconstrói a paisagem no tempo escriturado pela cultura e pela transformação social.

Não se pode deixar de enxergar a labuta do trabalhador. O terciário de barraquinha, as crianças que engraxam, os idosos que vendem picolés, os adolescentes que vigiam veículos, como os donos de pousadas e de hotéis, mostram a diferenciação do trabalho e a sua correspondente urgência na construção da existência.

Trata-se, ainda, de perceber que o comando festivo se altera de lugar. Cada vez mais o entorno da Igreja Nova é gravitado por pessoas, vendedores, peregrinos e devotos. E a promessa de construção de um novo templo já repercute nos valores dos imóveis e no deslocamento dos lugares festivos. Nesta ordem, o poder de conduzir o movimento festivo e a resistência colocam em cena um conflito entre a liderança religiosa e antigos moradores da cidade.

Assim, o componente financeiro, mercadológico e político ferve o imaginário festivo, golpeia lances sobre os rumos e as tendências vindouras do evento. Posições que defendem um catolicismo popular e posições que defendem o catolicismo afeito aos padrões midiáticos evidenciam contendas de moradores, romeiros e rezadores.

Romeiros estilizados; vendedores; policiais; prostitutas; camponeses; fazendeiros; jovens urbanos; crianças pobres; Pessoas com Deficiência e suas vozes, cores, movimentos e símbolos. Além disso, sujeitos como artistas, cordelistas, cantores amadores encenam a rica dimensão simbólica da Festa/Romaria de Trindade e mostram a face diversa de Goiás.

\section{REFERÊNCIAS BIBLIOGRÁFICAS}

ALMEIDA, M. G de. Diversidade paisagística e identididades territoriais e culturais - Brasil sertanejo. In: ALMEIDA, M, G de.; CHAVEIRO, E, F.; BRAGA, H, C. Geografia e cultura: os lugares da vida e a vida dos lugares. Goiânia, Vieira, 2008. p.47-74.

ANTUNES, R. Os sentidos do trabalho: ensaio sobre a afirmação e a negação do trabalho. São Paulo: Boitempo, 2009. 
ASSESSORIA DE IMPRENSA DO SANTUÁRIO BASÍlLICA. Cidade de Trindade

$\begin{array}{lllll}\text { comemora } & 92 & \text { anos. } & \text { 2012. }\end{array}$

$<\mathrm{http}: / / \mathrm{www} \cdot$ paieterno.com.br/?class=Noticias\&method=onListarDetalhes\&id=3166>.

Acesso em 20/06/2013.

CHAVEIRO, E, F. O cerrado em disputa: sentidos culturais e práticas sociais contemporâneas. In: ALMEIDA, M, G de.; CHAVEIRO, E, F.; BRAGA, H, C. Geografia e cultura: os lugares da vida e a vida dos lugares. Goiânia, Vieira, 2008. p.75-97.

COELHO, T. O. O comércio varejista periódico na Festa de Trindade, GO: suas transformações. Boletim Goiano de Geografia, Goiânia, v. 23 nº 2, p.243-267, jul./dez. 2003

JAKOBSEN, k. A dimensão do trabalho informal na América Latina e no Brasil. JAKOBSEN, k.; et. al. (Org.). Mapa do trabalho informal: perfil socioeconômico dos trabalhadores informais na cidade de São Paulo. São Paulo: Editora Fundação Perseu Abramo, 2001. p.13-18.

JORNAL OPÇÃO. Goiás terá uma das maiores basílicas do Brasil. 2017. Diponível em: $<$ https://www.jornalopcao.com.br/reportagens/goias-tera-uma-das-maiores-basilicas-dobrasil-86929/>. Acesso em: 20/03/2017.

LOPES, D. S. X. de B. Trindade: "a capital da fé" - turismo religioso em Trindade -GO. Brasília-DF. 2011. 50 f. Especialização (Especialização em formação de professores e pesquisadores em turismo e hospitalidade) - Universidade de Brasília, Brasília, 2006.

MAIA, C. E. S.; COELHO, T. O. Tradições da roça na Festa do Divino Pai Eterno em

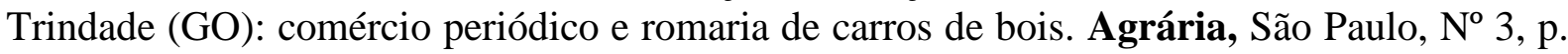
103-122, 2006.

MAIA, C. E. S. Informalidade e ilegalidade: faces e disfarces na economia urbana. Boletim Goiano de Geografia, Goiânia, v. 19, n. 2, p. 99-117, jan./dez. 1999.

MURILO, J. Romaria dos milhões. 2013. Disponível em: $<$ http://tribunadoplanalto.com.br/index.php?option=com_content\&view=article\&id=9872:ro maria-dos-milhoes\&catid=64:comunidades\&Itemid=6>. Acesso em: 28/07/2013.

PINTO, C. S. de O. A. Turismo religioso - potencial de desenvolvimento turístico da vila de Arcozelo, Vila Nova de Gaia. Lisboa. 2011. 118 f. Dissertação (Mestrado em Estratégias de Desenvolvimento Turístico) - Universidade Lusófona de Humanidades e Tecnologias, Lisboa, 2011.

RODRIGUES, R. J. Urbanização do/no Cerrado: um olhar sobre a cidade de Trindade-GO. Mimeografado, Goiânia (GO), 2018.

SABINO, W. Projeto deixa Trindade mais limpa na Romaria. 2013. Disponível em: <http://www.go.agenciasebrae.com.br/noticia/21088363/institucional/projeto-deixa-trindademais-limpa-na-romaria/> . Acesso em: 28 de Jul./2013.

SECRETARIA DE PLANEAMENTO DO ESTADO DE GOIÁS. Ranking dos municípios goianos $2005 . \quad$ Disponível em: <http://www.seplan.go.gov.br/sepin/pub/rank/2005/trindade.pdf>. Acesso: em 20/06/2013. 
TAVARES, M. A. Trabalho informal: os fios (in)visíveis da produção capitalista. Revista Outubro, No. 7, p. 49-60. 2002.

Recebido em Outubro de 2017

Aprovado em Maio de 2018

Publicado em Julho de 2018 